\title{
Ultrasonic and Densimetric Titration Applied for Acid-base Reactions
}

\author{
Andrzej BURAKOWSKI $I^{\dagger}$ and Jacek GLIŃSKI \\ Faculty of Chemistry, University of Wrocław, F. Joliot-Curie 14, 50-383 Wroctaw, Poland
}

\begin{abstract}
Classical acoustic acid-base titration was monitored using sound speed and density measurements. Plots of these parameters, as well as of the adiabatic compressibility coefficient calculated from them, exhibit changes with the volume of added titrant. Compressibility changes can be explained and quantitatively predicted theoretically in terms of Pasynski theory of non-compressible hydrates combined with that of the additivity of the hydration numbers with the amount and type of ions and molecules present in solution. It also seems that this development could be applied in chemical engineering for monitoring the course of chemical processes, since the applied experimental methods can be carried out almost independently on the medium under test (harmful, aggressive, etc.).
\end{abstract}

Keywords Sound speed, compressibility, density, densimetric titration, acoustic titration, hydration number, monitoring of chemical reactions

(Received April 23, 2014; Accepted June 12, 2014; Published August 10, 2014)

\section{Introduction}

The sound speeds in liquids together with their densities allow one to calculate the adiabatic compressibility coefficients with very high accuracy, when applying the Laplace equation,

$$
\kappa_{\mathrm{S}}=\frac{1}{c^{2} \rho},
$$

where $\kappa_{\mathrm{S}}=-\frac{1}{V}\left(\frac{\partial V}{\partial P}\right)_{\mathrm{S}}$ is the adiabatic compressibility coefficient, $c$ the speed of sound, $\rho$ the density, $V$ the volume, $P$ the pressure and the subscript $\mathrm{S}$ denotes the adiabatic condition. The compressibility of a liquid system is a measure of its local rigidity (in molecular scale), and depends strongly on intermolecular interactions as well as the medium microscopic structure. Thus, this quantity is widely applied for determining solvation numbers using an idea of Pasynski first postulated for electrolytes, ${ }^{1}$ and further also for non-electrolytes in water. ${ }^{2}$

The preciseness of a sound velocity determination, the relatively small amount of liquid needed for it, the opportunity of conducting measurement on-line and inside a chemical reactor makes this kind of measurement very promising in monitoring technological processes. This is sometimes done, mainly for polymerization reactions ${ }^{3}$ or the solidification process. ${ }^{4}$ Acoustic waves are used for characterizing the particle size distribution in slurries, ${ }^{5}$ to identify the onset conditions of wax and asphaltene precipitation from reservoir fluids used in the petroleum industry, ${ }^{6}$ or to monitor the gelatinization of starch, ${ }^{7,8}$ also in a titration-like experiment.

However, there are very limited data in literature concerning the acoustical monitoring of simple reactions, like acid-base, reduction-oxidation, or the formation of complexes. The same

† To whom correspondence should be addressed.

E-mail: andrzej.burakowski@gmail.com concerns the monitoring of chemical reactions using density measurements. These experiments can be performed using vibrating U-shaped vessels; the frequency of the resonance vibration depends on the mass of liquid in the vessel, i.e. on its density (while the volume of vessel is known). Such a method needs a small amount of sample, and can be used in a continuous and computerized process. Thus, it seems to also be useful in monitoring the course of chemical reactions. However, only few papers have exploited such an idea. Csákvári et al. developed densimetric titration with the aim to explain the potentiometric behavior of poly $(\mathrm{N}$-vinylpyrrolidone- $\mathrm{CO}$-maleic acid) titrated by $\mathrm{NaOH}$ or $\mathrm{KOH}$. They found differences in the dependences of the apparent molar volumes of solution on the degree of titration between the two titrants used. ${ }^{9}$ Umebayashi et al. ${ }^{10}$ measured the apparent molar volumes of $\mathrm{N}, \mathrm{N}$ dimethylformamide solutions of zinc salt by adding to it thiocyanate anions as complexing agents, but the results are not very spectacular. Much more convincing are the results of Čeleda and Plzák, ${ }^{11}$ who titrated $\mathrm{Ni}^{2+}, \mathrm{Zn}^{2+}$ and $\mathrm{Cd}^{2+}$ salts in an ammonia medium using $\mathrm{CN}^{-}$anions and observed exchange of ligands in the coordination spheres of cations, perfectly consistent with the expected stoichiometry of the reaction $\left(\left[\mathrm{Me}\left(\mathrm{NH}_{3}\right)_{\mathrm{x}}\right]^{2+} \rightleftharpoons\left[\mathrm{Me}(\mathrm{CN})_{4}\right]^{2-}\right)$. Direct densimetric titration was applied by Cerar and Škerjanc for ethylenemalonic acid, ${ }^{12}$ who observed a rapid change in the slope of the dependence of the density on the amount of added titrant.

Acoustic titration-like experiments were also made in order to characterize the acid-induced denaturation of staphylococcal nuclease at different urea concentrations, ${ }^{13}$ to study the binding of the cationic surfactant dodecyltrimethylammonium bromide to short fragments of DNA in dilute solutions at $1 \mathrm{mM} \mathrm{NaCl},{ }^{14}$ to analyze the binding of alamethicin to unilamellar DMPC vesicles, ${ }^{15}$ and also to study interactions of $\mathrm{Co}\left(\mathrm{NH}_{3}\right)_{6}{ }^{3+}$ with calf thymus DNA ${ }^{16}$ and $\mathrm{Cs}^{+}$and $\mathrm{Mg}^{2+}$ with polynucleotides. ${ }^{17}$

All of the above listed reports encouraged us to test if sound speed or density measurements can be applied for monitoring simple reactions, like acid-base titration, and how to describe 
the observed changes. The choice of the experimental methods arises from their high accuracy as well as the possibility of further automation and computerization.

\section{Experimental}

Hydrochloric acid and sodium hydroxide $1 \mathrm{~mol} / \mathrm{L}$ standard volumetric solutions and glycine $>99,5 \%$ p.a. were from $\mathrm{POCh}$, Gliwice, Poland. Succinic acid p.a. was from Reanal, Budapest, Hungary and sodium succinate hexahydrate $>99 \%$ was from BDH Chemicals Ltd., Poole, England. Glycine hydrochloride and sodium glycinate were prepared by mixing equimolar amounts of glycine and hydrochloric acid or sodium hydroxide solutions.

The speed of sound was measured using a computer-steered OPKUD 01/100 apparatus (Optel, Wrocław, Poland), with the absolute accuracy being better than $\pm 0.2 \mathrm{~m} \mathrm{~s}^{-1}$ and with the same precision, described elsewhere. ${ }^{18}$ The initial sample was placed in thermostated stainless and acid-resistant vessel, and the titrant was gradually added using a micropipette. After the addition of each portion of the titrant, the content was mechanically stirred. Measurements were performed at a constant temperature of $298.15 \mathrm{~K}$, stabilized by a precision Julabo F25-ME (Germany) thermostat with an accuracy of $\pm 0.01 \mathrm{~K}$.

The density was measured using a vibrating tube Automatic Density Meter DDM 2911 (Rudolph Research Analytical, Hackettstown, NJ) with an accuracy of better than $\pm 0.05 \mathrm{~kg} \mathrm{~m}^{-3}$. In this experiment, samples were placed in a container connected to the densimeter using a peristaltic pump, which ensured continuous circulation of the liquid. The titrant was added gradually to the container using a micropipette, and the sample was stirred using a magnetic stirrer.

\section{Results and Discussion}

When plotting sound speeds $v s$. the degree of titration, one obtains characteristic plots with less or more distinct inflections, corresponding to the equivalence points of titration, as illustrated in Fig. 1. Titration was always performed in both directions (acid + base and base + acid). Note that rather minor total changes of slopes of the sound speeds $v s$. titration degree occurred after the equivalence point(s). Keep in mind that both glycine and succinic acid are two-proton acids, i.e. one should observe two equivalence points for these compounds (at 100 and 200 titration degrees). Their deprotonation constants are: $K_{1}=10^{-2.35}$ and $K_{2}=10^{-9.87}$ (glycine hydrochloride), $K_{1}=10^{-4.16}$ and $K_{2}=10^{-5.61}$ (succinic acid). ${ }^{19}$

Note that a relatively low variability occurred even at high initial concentrations of the reagents. It seems that the sound speed is not the best parameter for monitoring this kind of reaction. Thus, identical titrations were performed with densimetric monitoring; the results are shown in Fig. 2.

Here also the variability was rather limited, particularly for sodium glycinate $+\mathrm{HCl}$ (Fig. 2f), but the observed changes at the equivalence points are much more spectacular.

The sound speed changes that occur with the degree of titration cannot be predicted theoretically. It seems possible for density if applying partial molar volumes of the components, but the conditions of our experiment which are typical of the titration used for quantitative analysis - high total concentration of ions, changing mutual concentrations of components - make such calculations difficult, and their results questionable.
However, a theoretical prediction is possible for the adiabatic compressibility coefficient of a liquid solution.

In our recent papers it was shown that the hydration number of a solute is additive with the constituents of the solute molecule ${ }^{20,21}$ or, in case of an ionic solution, with the concentration and type of ions present in solution..$^{22}$ The most reliable method ${ }^{23}$ for determining the hydration numbers seems to be the method of Pasynski cited above. ${ }^{1,2}$ If the hydrate is less compressible than the solvent, one observes a decrease in the total compressibility caused by the addition of a solute, because some amount of water solvent becomes less compressible after being incorporated into the hydration shell. Simple manipulations lead to the formula

$$
n_{\mathrm{h}}=\frac{n_{\mathrm{H}_{2} \mathrm{O}}\left(\kappa_{\mathrm{S}}-\kappa_{\mathrm{S}, \mathrm{H}_{2} \mathrm{O}}\right)}{n_{\text {solute }}\left(\kappa_{\mathrm{S}, \text { hydrate }}-\kappa_{\mathrm{S}, \mathrm{H}_{2} \mathrm{O}}\right)},
$$

where $n_{\mathrm{h}}$ is the hydration number; $n_{\mathrm{H}_{2} \mathrm{O}}, n_{\text {solute }}$ are the number of moles of water and of the solute in the mixture, respectively; $\kappa_{\mathrm{S}}$, $\kappa_{\mathrm{S} \text {,hydrate }}, \kappa_{\mathrm{S}, \mathrm{H}_{2} \mathrm{O}}$ are the adiabatic compressibility coefficients of the solution, hydrate and pure water, respectively. ${ }^{24}$ Assuming, following Pasynski, that $\kappa_{\mathrm{S} \text {,hydrate }}$ is equal to zero (i.e. hydrated solute is incompressible), one obtains a simplified equation,

$$
n_{\mathrm{h}}=\frac{n_{\mathrm{H}_{2} \mathrm{O}}\left(\kappa_{\mathrm{S}, \mathrm{H}_{2} \mathrm{O}}-\kappa_{\mathrm{S}}\right)}{n_{\text {solute }} \kappa_{\mathrm{S}, \mathrm{H}_{2} \mathrm{O}}} .
$$

The idea of a direct link between the hydration number and the architecture of the solute molecule was well proved for simple organic molecules, ${ }^{25}$ as well as for amino acids in water or in an electrolytic medium. ${ }^{26,27}$

This idea can be inverted: if one knows the concentrations of ions or other solutes and their theoretical contributions to the total observed hydration number for a given substance, it is possible to calculate the compressibility of the solution, $\kappa_{\mathrm{S}}$. Thus, we calculated the changes in the compressibility of our systems during titration from the experimental sound speeds and densities using Eq. (1), and compared the results with theoretical values calculated from the hydration numbers of individual ions taken from literature. 22,27 These contributions are listed in Table 1.

The procedure was as follows: for each experimental point, by knowing the ionic composition of the solution, the amount of water molecules involved in the hydration spheres of ions was calculated. This number was subtracted from the total number of water molecules, and the resulting compressibility was calculated as a respective part of that for pure water. In other words, the original Pasynski equation (Eq. (3)) was transformed in the following way:

$$
\kappa_{\mathrm{S}, \text { calc. }}=\kappa_{\mathrm{S}, \mathrm{H}_{2} \mathrm{O}}\left(1-\frac{n_{\mathrm{h}} n_{\text {solute }}}{n_{\mathrm{H}_{2} \mathrm{O}}}\right)
$$

for one solute, and

$$
\kappa_{\mathrm{S}, \text { calc. }}=\kappa_{\mathrm{S}, \mathrm{H}_{2} \mathrm{O}}\left(1-\frac{\sum_{i=1}^{N} n_{\mathrm{h}, \mathrm{i}} n_{\mathrm{i}}}{n_{\mathrm{H}_{2} \mathrm{O}}}\right)
$$

for $N$ solutes. Here, index $i$ numbers the ions.

The results of such a simple simulation is shown in Fig. 3, where experimental values of the compressibility (points) are compared to the calculated ones (lines).

The differences in the absolute values of the experimental and 


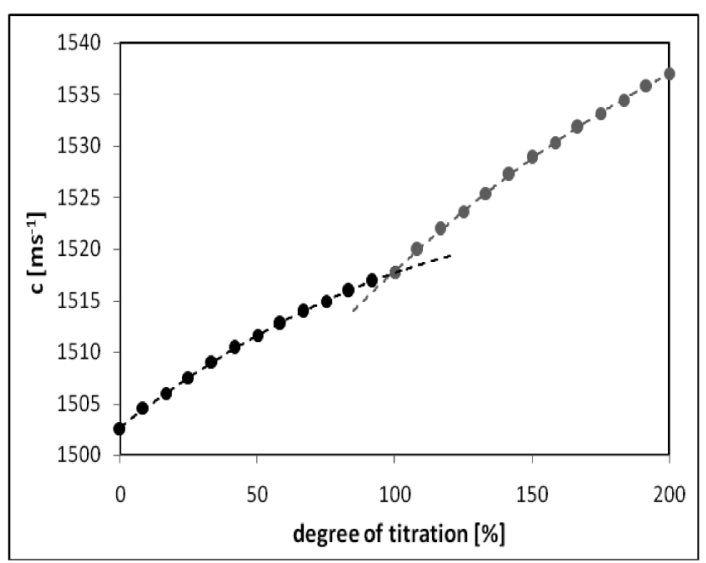

a)

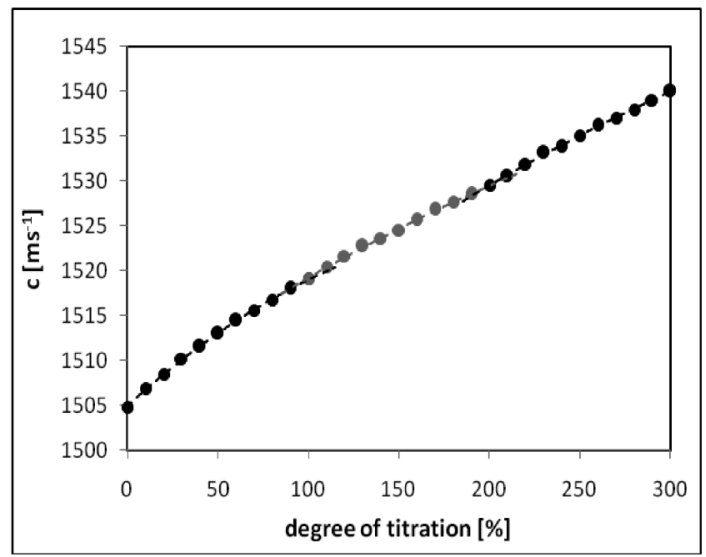

c)

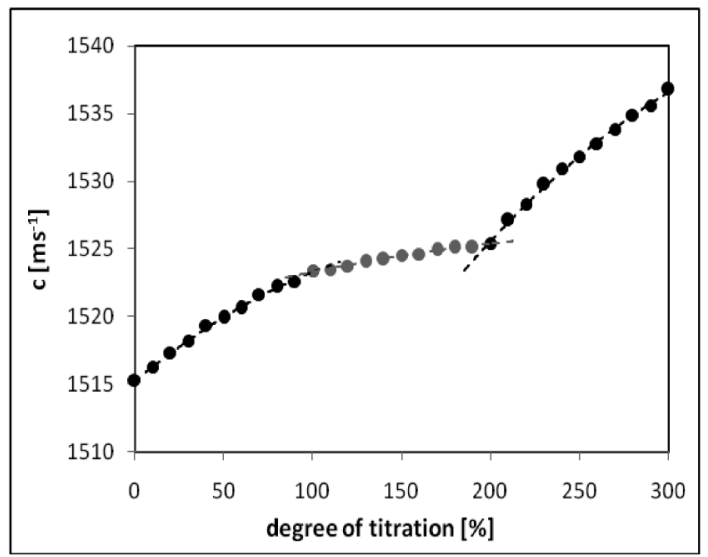

e)

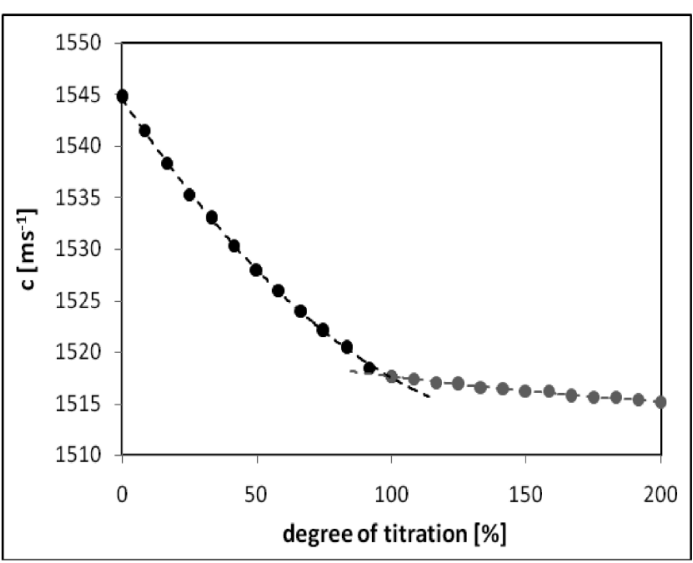

b)

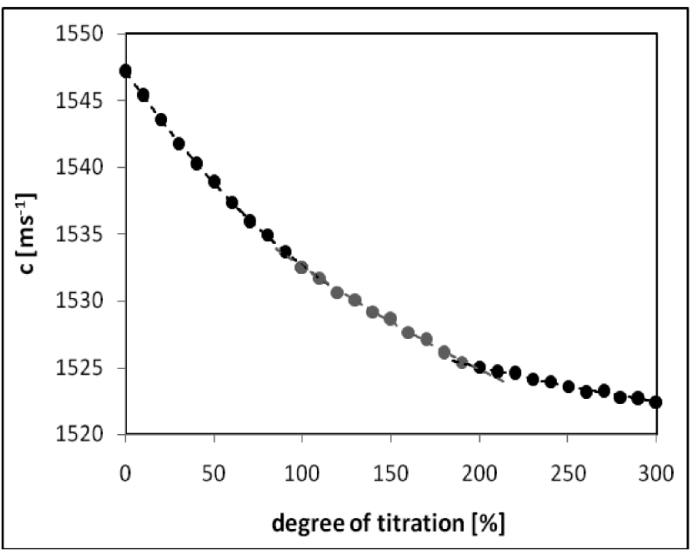

d)

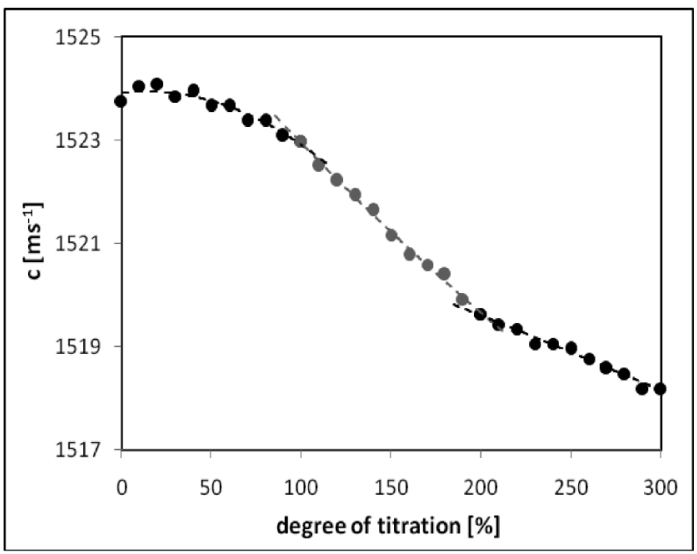

f)

Fig. 1 Sound speed $v s$. degree of titration for the systems under investigation: a) $0.5 \mathrm{M} \mathrm{HCl}+1 \mathrm{M}$ $\mathrm{NaOH}$; b) $0.5 \mathrm{M} \mathrm{NaOH}+1 \mathrm{M} \mathrm{HCl}$; c) $0.3 \mathrm{M}$ succinic acid $+1 \mathrm{M} \mathrm{NaOH}$; d) $0.3 \mathrm{M}$ sodium succinate + $1 \mathrm{M} \mathrm{HCl}$; e) $0.3 \mathrm{M}$ glycine hydrochloride $+1 \mathrm{M} \mathrm{NaOH}$; f) $0.3 \mathrm{M}$ sodium glycinate $+1 \mathrm{M} \mathrm{HCl}$.

theoretical compressibilities arise most probably from the fact that the ionic contributions have been determined for very diluted electrolytic solutions, where the ionic strength is close to zero. Moreover, they have been determined as an average of many, two-component systems (water plus electrolyte), i.e., with minimized possibility of specific interionic interactions. Last but not least, titrations were carried without thermostating the titrant (which was added by a micropipette); this is evidently a non-neglectable source of the inconsistency between the real mass and that calculated from the volume and density.

Independent on that, the reproduction of the experimental dependences by theory is surprisingly good. This is additional proof for the validity of the hypothesis of additivity of the hydration number on the composition of a solution, as well as 


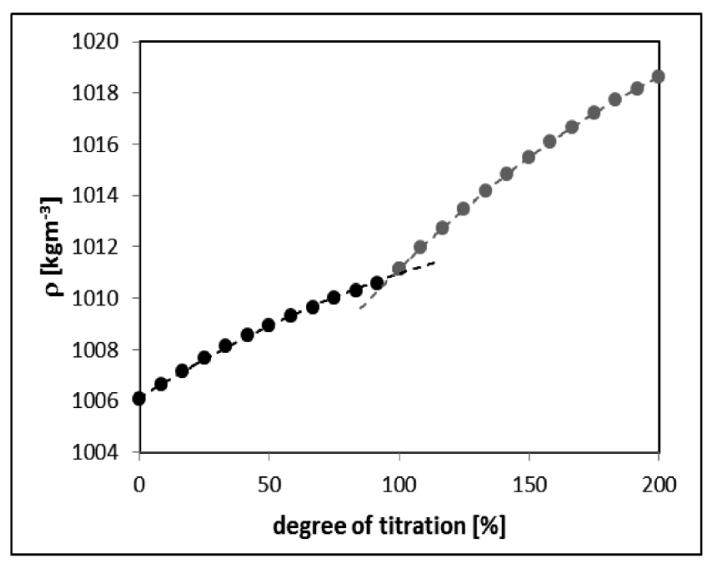

a)

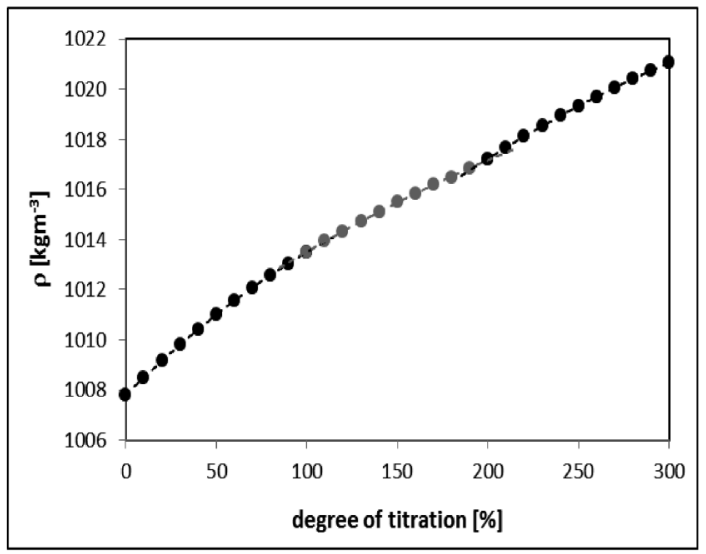

c)

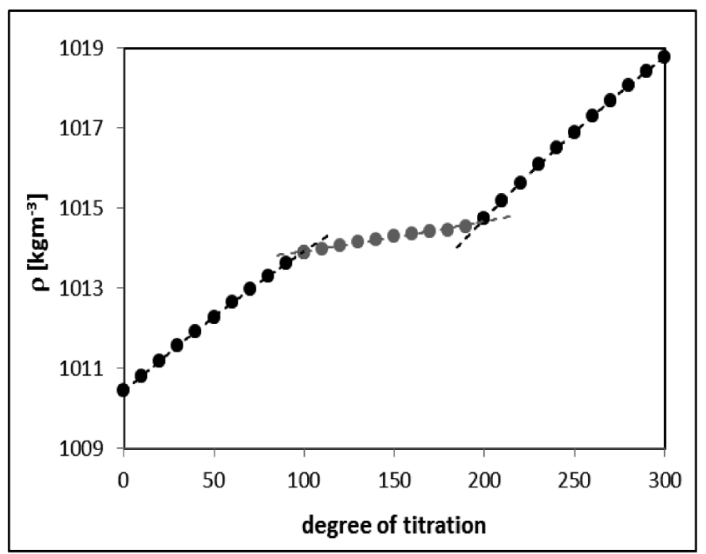

e)

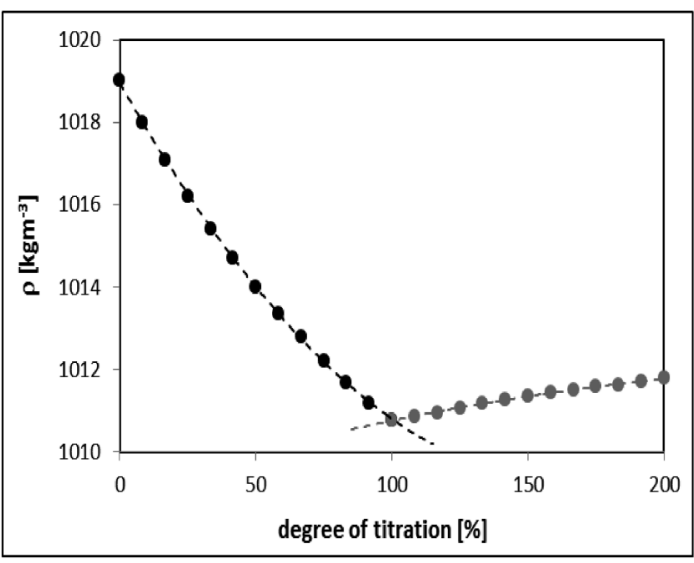

b)

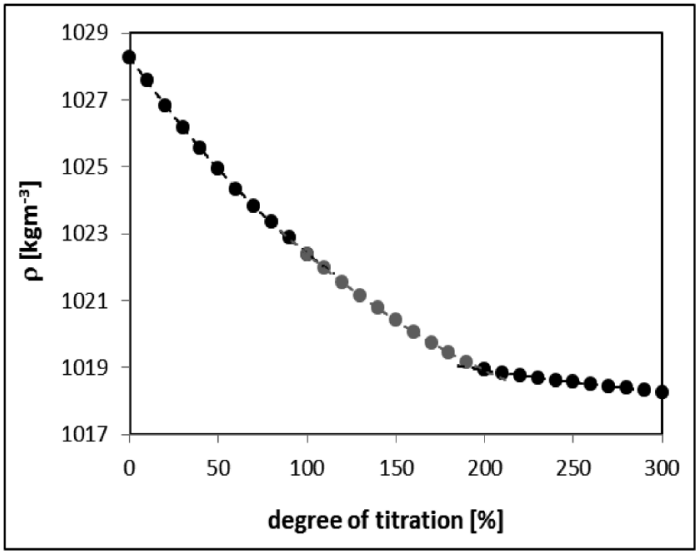

d)

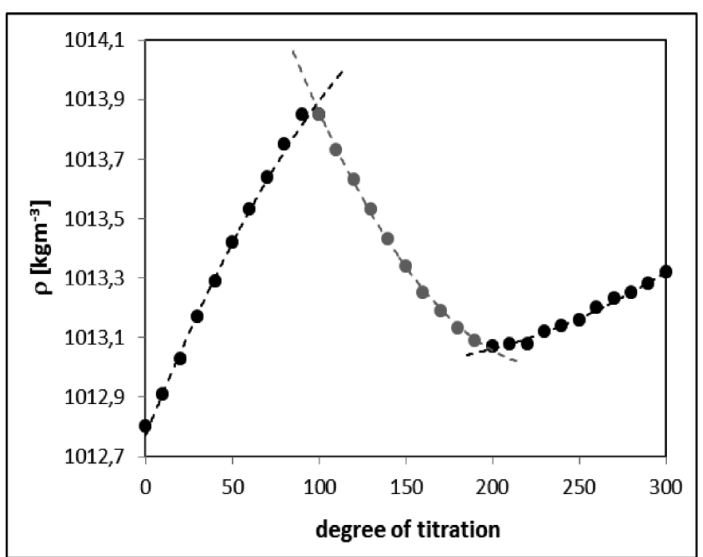

f)

Fig. 2 Density $v s$. degree of titration for the systems under investigation: a) $0.5 \mathrm{M} \mathrm{HCl}+1 \mathrm{M} \mathrm{NaOH}$; b) $0.5 \mathrm{M} \mathrm{NaOH}+1 \mathrm{M} \mathrm{HCl}$; c) $0.3 \mathrm{M}$ succinic acid $+1 \mathrm{M} \mathrm{NaOH}$; d) $0.3 \mathrm{M}$ sodium succinate $+1 \mathrm{M}$ $\mathrm{HCl}$; e) $0.3 \mathrm{M}$ glycine hydrochloride + $1 \mathrm{M} \mathrm{NaOH}$; f) $0.3 \mathrm{M}$ sodium glycinate $+1 \mathrm{M} \mathrm{HCl}$.

for the validity of the (often criticized) assumption of a noncompressible hydration sphere of ions.

From a practical point of view, our results show the following:

a) Density seems to be more sensible for hydration than sound speed.

b) For practical applications, it is not necessary to determine the apparent molar volumes when analyzing the results, like it was done before. ${ }^{10,12}$ c) Because of the relatively low variabilities of sound speeds and densities with the titration degree, the measurements should be carried under almost isothermal condition.

d) While the compressibility dependence on the sound speed is stronger (see Eq. (1)), the changes in a solution are better monitored by the density. However, for simulating the changes it is necessary to calculate the compressibility.

e) The abruptnesses of sudden changes in slopes observed in 


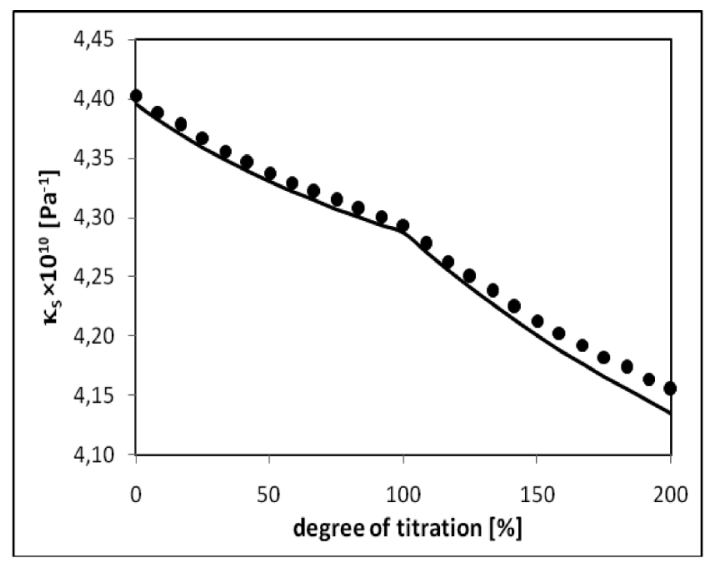

a)

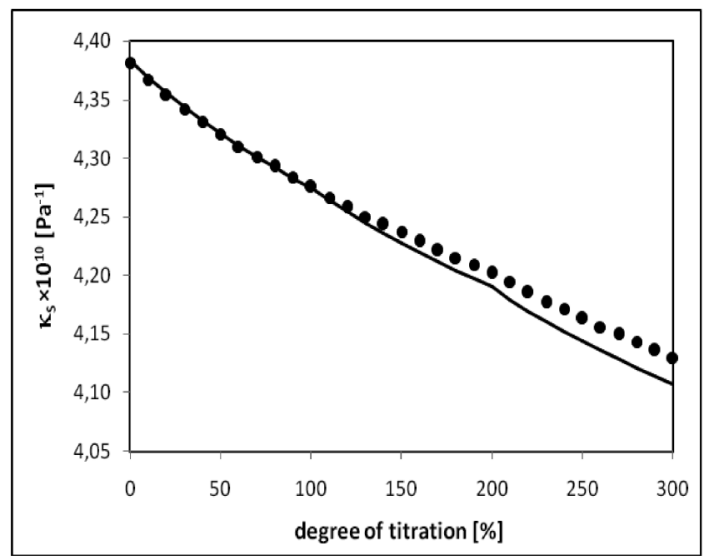

c)

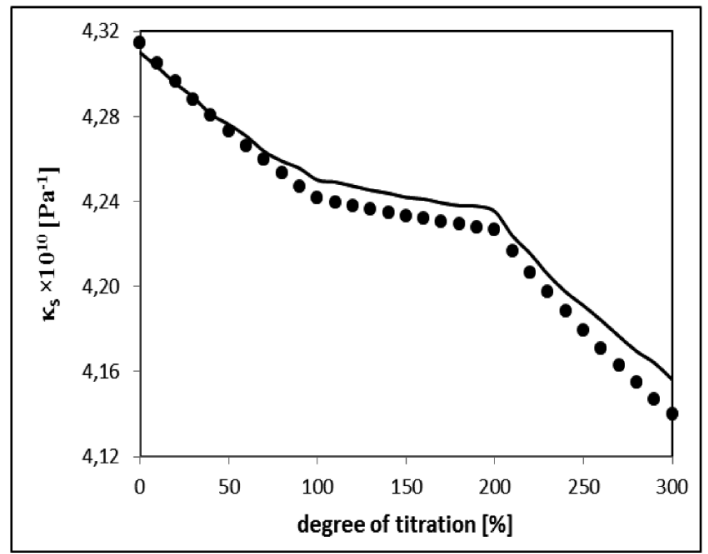

e)

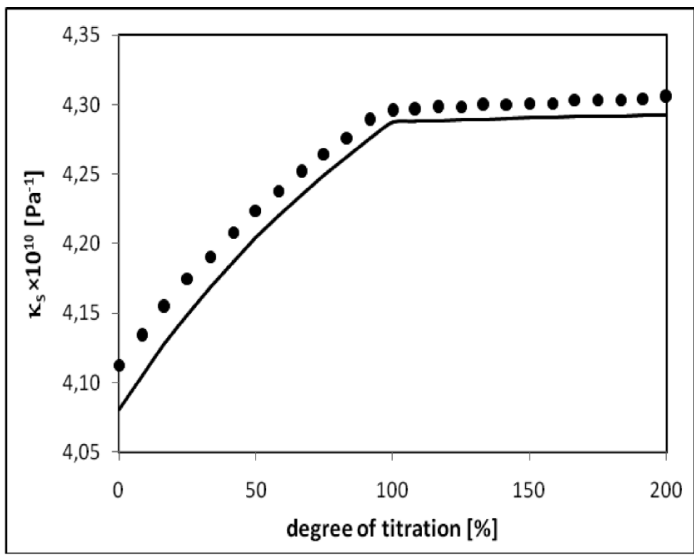

b)

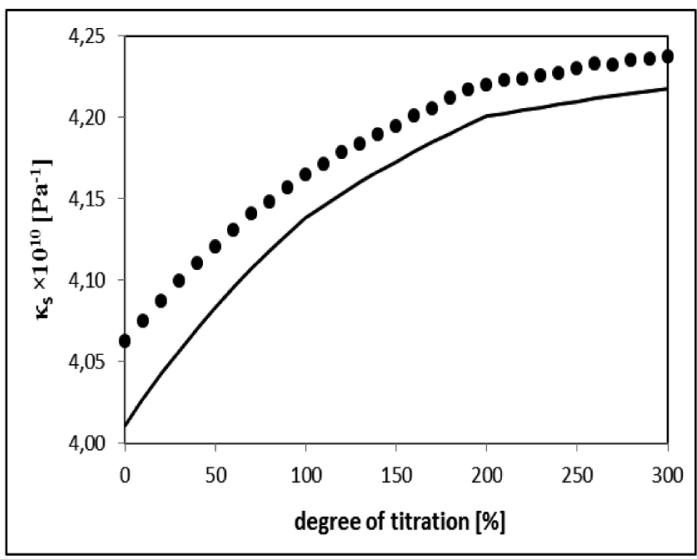

d)

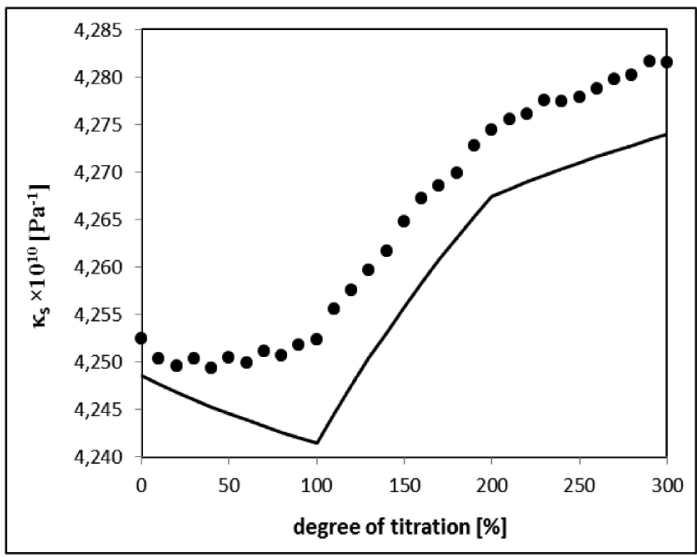

f)

Fig. 3 Adiabatic compressibility coefficient $v s$. degree of titration for the systems under investigation: a) $0.5 \mathrm{M} \mathrm{HCl}+1 \mathrm{M} \mathrm{NaOH}$; b) $0.5 \mathrm{M} \mathrm{NaOH}+1 \mathrm{M} \mathrm{HCl}$; c) $0.3 \mathrm{M}$ succinic acid + $1 \mathrm{M} \mathrm{NaOH}$; d) $0.3 \mathrm{M}$ sodium succinate $+1 \mathrm{M} \mathrm{HCl}$; e) $0.3 \mathrm{M}$ glycine hydrochloride $+1 \mathrm{M} \mathrm{NaOH}$; f) $0.3 \mathrm{M}$ sodium glycinate $+1 \mathrm{M} \mathrm{HCl}$. Points are experimental; lines are calculated assuming ionic contributions to the total hydration numbers listed in Table 1.

the Figures are not correlated with the classical titration $\mathrm{pH}$ jump. For example, the first jump for glycine hydrochloride is much stronger than the second one, but Figs. 1e, 2e and $3 e$ do not suggest this.

f) Because of differences in the hydration numbers of ions, the sensibility of this method of titration should be different if using different titrants (for instance $\mathrm{KOH}$ instead of $\mathrm{NaOH}$ ), which is not the case for classical pH-metric titrations. This aspect will be a subject of our future tests. It is also interesting that in the literature densimetric measurements are often performed with an additional amount of inert strong electrolytes. This is done in order to stabilize the 
Table 1 Ionic hydration numbers used in calculations

\begin{tabular}{lc}
\hline \multicolumn{1}{c}{ Ion } & $n_{\mathrm{h}}$ \\
\hline $\mathrm{Na}^{+}$ & 4.0 \\
$\mathrm{Cl}^{-}$ & 3.1 \\
$\mathrm{H}^{+}$ & -1.0 \\
$\mathrm{OH}^{-}$ & 5.9 \\
$\mathrm{HOOC}^{-} \mathrm{CH}_{2}-\mathrm{CH}_{2}-\mathrm{COOH}^{\mathrm{a}}$ & $3.9^{\mathrm{a}}$ \\
$\mathrm{HOOC}-\mathrm{CH}_{2}-\mathrm{CH}_{2}-\mathrm{COO}^{-}$ & $6.9^{\mathrm{a}}$ \\
${ }^{-} \mathrm{OOC}-\mathrm{CH}_{2}-\mathrm{CH}_{2}-\mathrm{COO}^{-}$ & $10.9^{\mathrm{a}}$ \\
${ }^{+} \mathrm{H}_{3} \mathrm{~N}-\mathrm{CH}_{2}-\mathrm{COOH}^{-}$ & 3.6 \\
${ }^{+} \mathrm{H}_{3} \mathrm{~N}-\mathrm{CH}_{2}-\mathrm{COO}^{-}$ & 5.5 \\
$\mathrm{H}_{2} \mathrm{~N}-\mathrm{CH}_{2}-\mathrm{COO}^{-}$ & 5.4 \\
\hline
\end{tabular}

a. Unpublished data.

ionic medium and to reduce concentration changes of the molar volumes. ${ }^{11}$ However, a large amount of ions in solution engages most of the water solvent molecules in their hydration spheres, and thus reducing the relative variability of the total compressibility of the system. In light of that, when measuring the compressibility and not exclusively density, such regulation of the ionic strength can disturb the measurement.

\section{Conclusions}

The titration of acids and bases can be directly monitored using the sound speed or density. Both of these methods are ideal, but not often applied tools in the practice of such experiments, mainly because they can be carried out almost independently of the medium under test (for example aggressive, harmful or turbid liquids). The density seems to be more sensitive as the monitoring parameter, but the compressibility (calculated from density and sound speed data) can be successfully simulated before an experiment using the method presented in this paper, and thus used to predict the applicability of this method for monitoring the chemical processes.

\section{References}

1. A. G. Pasynski, Acta Physicochim. URSS, 1938, 8, 385.

2. A. G. Pasynski, Acta Physicochim. URSS, 1947, 22, 137.

3. O. Kammona, E. G. Chatzi, and C. Kiparissides, J. Macromol. Sci., Rev. Macromol. Chem. Phys., 1999, C39,
57.

4. E. P. Papadakis, J. Appl. Phys., 1974, 45, 1218.

5. A. S. Dukhin and P. J. Goetz, Colloid Surf., A, 1998, 144, 49.

6. S. O. Colgate and A. Sivaraman, Int. J. Thermophys., 1996, $17,15$.

7. L. Lehmann, E. Kudryashov, and V. Buckin, Prog. Colloid Polym. Sci., 2004, 123, 136.

8. E. Kudryashov, C. Smyth, G. Duffy, and V. Buckin, Prog. Colloid Polym. Sci., 2000, 115, 287.

9. E. Csákvári, M. Azori, and F. Tüdös, Polym. Bull., 1984, 12, 553.

10. Y. Umebayashi, R. Kanzaki, and S. Ishiguro, J. Chem. Soc., Faraday Trans., 1997, 93, 2167.

11. J. Čeleda and Z. Plzák, Collect. Czech. Chem. Commun., 1971, 36, 3715.

12. J. Cerar and J. Škerjanc, Acta Chim. Slov., 1998, 45, 103.

13. R. Filfil and T. V. Chalikian, J. Mol. Biol., 2000, 299, 827.

14. S. Morrissey, E. D. Kudryashov, K. A. Dawson, and V. A. Buckin, Prog. Colloid Polym. Sci., 1999, 112, 71.

15. M. Jäger, U. Kaatze, E. Kudryashov, B. O’Driscoll, and V. Buckin, Spectroscopy, 2005, 20, 24.

16. B. I. Kankia, V. Buckin, and V. A. Bloomfield, Nucleic Acids Res., 2001, 29, 2795.

17. V. A. Buckin, B. I. Kankiya, A. P. Sarvazyan, and H. Uedaira, Nucleic Acids Res., 1989, 17, 4189.

18. A. Burakowski, J. Gliński, B. Czarnik-Matusewicz, P. Kwoka, A. Baranowski, K. Jerie, H. Pfeiffer, and N. Chatziathanasiou, J. Phys. Chem. B, 2012, 116, 705.

19. "CRC Handbook of Chemistry and Physics", ed. R. C. Weast, 56th ed., 1975, CRC Press, Cleveland, Ohio, USA.

20. A. Burakowski and J. Gliński, J. Mol. Liq., 2008, 137, 25.

21. J. Gliński and A. Burakowski, Eur. Phys. J.: Spec. Top., 2008, 154, 275.

22. A. Burakowski and J. Gliński, Chem. Phys. Lett., 2009, $468,184$.

23. A. Burakowski and J. Gliński, Chem. Rev., 2012, 112, 2059.

24. J. Gliński and A. Burakowski, Chem. Phys. Lett., 2013, $566,21$.

25. A. Burakowski and J. Gliński, Chem. Phys., 2007, 332, 336.

26. A. Burakowski and J. Gliński, Acta Phys. Pol., A, 2008 114, A39.

27. A. Burakowski and J. Gliński, J. Phys. Chem. B, 2010, 114, 12157. 